\title{
Cultural Economics, Innovation and Intellectual Property
}

Nicola C. Searle

\section{Introduction}

The combination of economics and the cultural and creative industries is a complicated one. The intangible nature of the cultural and creative industries does not lend itself to standard economic analysis of the utility and profitmaximising emphasis of neoclassical economics. Similar challenges occur in the economics of happiness, health, the environment and other areas marked by their intangible nature. Despite this awkward matching, the economic analysis of the cultural and creative industries, and the role of creativity, is a vibrant and growing area.

This chapter examines themes in what is known as cultural economics, with a particular focus on innovation, creativity and intellectual property (IP). It details emerging trends in economic analysis of the cultural and creative industries and highlights challenges that mainstream, neoclassical economic analysis faces when confronting characteristics of the creative industries.

\section{Terminology}

A great deal of energy in academic studies of the creative industries $(\mathrm{Cl})$, and related terms ${ }^{i}$, is spent on their definition. These are important discussions as the classification of industries, primarily through Standard Industrial Classifications, reflects political and social constructs of industry. While these nuances are important to wider debates, for the purposes of the chapter, this chapter focuses on four key terms: the creative industries, creativity, innovation, cultural economics, cultural policy and largely adopts the terminology as detailed in (Towse 2014) and (Towse 2010).

Creative industries indicates the UK government's Department for Media, Culture and Sport1998 definition consisting of advertising, antiques, architecture, crafts, design, fashion, film, leisure software, music, performing 
arts, publishing, software, and TV and radio (antiques has since been removed, DCMS (2015).

Creativity, discussed in Towse (2010), refers to the 'artistic creativity' defined by UNCTAD (Economy 2008) as, "artistic creativity involves imagination and a capacity to generate original ideas and novel ways of interpreting the world, expressed in text, sound and image."iii This chapter focuses on creativity as related to the creative industries. (Towse 2010) notes, "Creativity has thus come to be seen as the contemporary equivalent of innovation in the industrial age.,iv This chapter adopts a Shumpeterian approach to innovation as a wider concept than creativity. Schumpeter (1942) approaches innovation as 'creative destruction' in a, "process of industrial mutation-if I may use that biological term-that incessantly revolutionizes the economic structure from within, incessantly destroying the old one, incessantly creating a new one."

Schumpeter further describes examples of innovation as the launch of new products, opening of new markets, application of new methods, acquiring of new supply sources and new industry structures. In the singular as opposed to the general process, an innovation is typically described in economics as an applied invention. The emphasis, like with creativity, is on the idea of 'new.'

Finally, this chapter will use cultural economics as the branch of economics concerned with the application of economic principles to the study of the cultural and creative industries. This is in line with the Towse (2010) definition, but excludes the cultural economics sub-disciplines as defined by the Journal of Economic Literature (JEL) codes of the economics of religion, economic ideologies and social economy. Likewise, the use of the term cultural policy is broadly in line with Towse $(2010,2014)$ definition of cultural policy to include policies related to the creative industries, including funding, taxation, measurement, regulations, and, to explicitly reflect recent trends in scholarship, IP.

This approach is not without its critics as Garnham (2005) notes. He adopts "arts and media policy" instead of "cultural policy," as the later is not neutral. Indeed, "arts and media policy" may be a better descriptor of the economic definition, but one that has not been adopted by the literature. Hesmondhalgh 
(2005) also argues for including media policy as part of policy; tensions between these policy definitions are detailed in Hesmondhalgh and Pratt (2005.) In short, an economic approach to cultural policy examines government policy related to the cultural and creative industries.

To summarise, this chapter focuses on the creative industries as part of cultural policy, the economic study of the creative industries, and relates these analysis to innovation and creativity.

\section{Cultural Economics: Evolution and Critiques}

"Whenever economists study areas outside their traditional field, the economy, they run the danger of misperceiving what contribution they are able to make. Only if the choice of which aspects to study is carried out carefully can a useful and novel contribution on the part of economics be expected."

(Frey 1994)

Cultural economics as a discipline, in its current form ${ }^{v}$, gained currency in the 1960s with the works of William Baumol and William Bowen and their analysis of cost structure in the arts (Throsby 1994). Despite the half century that has passed since Baulmol, many economists still argue that economics continues to neglect, or fails to adapt to, the creative industries. Arguments of this sort can be found in Howkins (2002), Throsby and Throsby (2001) argue the outputs and structures of the creative industries do not fit into the neoclassical economic classification of goods and services, Caves (2000) argues economics has largely neglected the creative industries, and, finally, Stoneman (2010), who argues economics has largely excluded included creativity and 'soft' innovation in studies of innovation, amongst others.

The category of "Cultural Economics" was introduced under the "Miscellaneous" classification of JEL codes in 1991, following a move amongst economists to, "claim an independent category for their field." "vi (Cherrier 2014) JEL codes reflect mainstream economic disciplines and are in keeping with their North American origins. The structure of JEL, as do SIC, 
deliminates intradisciplinary boundaries. The bulk of what would be considered cultural policy or creative industries by the literature discussed in this chapter, falls under the JEL Z11, "Economics of the Arts and Literature" which is described as, "studies about economic issues related to the arts and literature, including demand, supply and pricing analysis." (AEA 2016) and Z18 "Cultural Economics; Public Policy," described as, "studies concerning public policy on art, religion and other matters in Z1 [the top level classification for Cultural Economics]." This, however, is an awkward fit for some of definitions of cultural policy and creative industries discussed earlier, which are perhaps better encompassed when including codes from other areas, such as L82 "Industry Studies: Services: Entertainment; Media (Performing Arts, Visual Arts, Broadcasting, Publishing, etc.)," 03 "Innovation; Research and Development; Technological Change; Intellectual Property Rights" and other codes addressing trade, international agreements, production and industrial organisation.

Written soon after the 1991 inclusion of cultural economics in JEL codes, Throsby (1994), describes, in JEL, the cultural industries to mean, "the arts, motion pictures, radio and television, and printing and publishing," which, very loosely, could be interpreted to include publicly funded arts organisations. He identifies the key focuses of cultural economics at the time as markets and public funding for art.

Since the formal recognition of cultural economics, there remains significant scope for the expansion of cultural economics. (Blaug 2001) and (Caves 2000) suggest that the areas of publishing and contracts, respectively, are underaddressed. Both areas are now garnering further attention as in Ghose et al (2006) and Baker and Evans (2013). More recent arguments, (Throsby 2012), (Müller et al. 2009) and (Towse, 2010 and 2014) suggest that cultural economics is coming into its own.

In the last decades of cultural economics, key themes of economic analysis have emerged. Rushton (2012) suggest that the starting premise of cultural economics is that the creative industries are a case of market failure. Frey (1994) suggests that analytical approaches progress in two main categories: 
the first being the relationship between sectors of spheres of society, and the second type being the rational choice approach to characterise the economic approach. He notes that cultural economic analysis typically combines the two approaches and uses the rational choice approach to analyse the effect of economic factors on the arts. (1994) suggests that analytical approaches progress in two main categories: the first being the relationship between sectors of spheres of society, and the second type being the rational choice approach to characterise the economic approach. He notes that cultural economic analysis typically combines the two approaches and uses the rational choice approach to analyse the effect of economic factors on the arts. (1994) suggests that analytical approaches progress in two main categories: the first being the relationship between sectors of spheres of society, and the second type being the rational choice approach to characterise the economic approach. He notes that cultural economic analysis typically combines the two approaches and uses the rational choice approach to analyse the effect of economic factors on the arts.

The application of these approaches is often concerned with cultural policy, industrial organisation, welfare economics, economic geography, economic growth and development, amongst others. In 1994, Throsby details the development of cultural economics from the 1960s and its adoption of neoclassical interpretations of taste, markets, demand, supply and labour markets to inform public policy. He predicted cultural economics would develop empirical insights to solve 'nontrivial theoretical and empirical problems' both in cultural policy and in economic methodologies in general, which, more than two decades later, continues to be thwarted by poor data. Towse (2010) describes a brief history of cultural economics as starting with subsidies for the arts, then moving through art markets, the development of theoretical models, the economics of museums, the introduction of the concept of the creative industries in the late 1900s, contractual and labour approaches, and a more recent focus on IP.

IP has recently become a more dominant theme in cultural economics, and economics in general, as interest in innovation and creativity lends itself to 
analysis of IP. In the 1990s, economists largely used IP to define the creative industries. As noted by Throsby (2001), IP as an industry's output was so central to meeting the definition, to the point that the 'copyright industries' and 'cultural industries' were virtually synonymous. In 1996, the Journal of Cultural Economics devoted an edition to IP. Since then, cultural economics is turning its attention further to IP. Of four key books published by cultural economists in 2000 and 2001, Caves (2000), Frey (2000), Throsby (2011) and Howkins (2001), Frey and Throsby have only cursory mentions of IP, Caves offers one chapter, of twenty two, and Howkins's text is devoted to the topic. As Towse (2006) notes, there is a wealth of areas to be explored in the application of cultural economics to IP. These themes are developed later in the chapter and highlight the insights that may be gleaned from combining economics, culture and IP.

\section{Audiences for Economic Analysis}

Several reviewers of the progress of cultural economics over the years have observed that many writers have begun their books or papers with an apology for presuming that economics might have anything useful to say about art. THROSBY 1994

The demand for economic analysis of cultural policy varies. In the Baulmol days of the 1960s, arts funding changes provided a ready audience. However, the interaction between economics and cultural policy has not enjoyed a smooth ride. Peacock, (2004), reflecting on three decades as an economist in arts and arts policy, details the challenges of economic analysis ${ }^{\mathrm{vii}}$ in creative industries and their use in policy. He notes the reluctance of vested interests, and special pleading by stakeholders, to admit that, "government support for the arts involves an opportunity cost."viii In particular, he argues that economics is widely accepted in policy for broadcasting, but that in preservation of works of art, buildings and the like, "there appears to be implacable opposition to the application of economic analysis designed to produce a rational system of pricing and investment which takes account of consumer interests. "ix He notes that institutions in publicly-funded parts of the 
cultural industries (e.g. museums) view themselves as 'guardians of public interest' and consider themselves to know better, or be more likely to know, what is in the interests of future generation. However, Hesmondhalgh (2005) suggests that economics enjoys a favoured position in UK politics starting in the late 1990s. Instead, he argues economic analysis had a ready audience in being a malleable tool to legitimise political stances. However, he repeats Peacock's argument and notes that, "Cultural policy has usually been strongly associated with the subsidised arts sector, whereas media and communications policy has tended to be analysed in terms of economics and politics." Whereas media and communications policy has traditionally been amenable to economic analysis, cultural policy has largely not. This again speaks to an on-going debate on the economics of the creative industries as part of cultural policy analysis.

Similar developments are to be found in the growing interaction between management and media studies. As with economics, the literature addressing the interaction of cultural and management perspectives has noted the general reluctance of traditional media studies to the use of market or industrial terminology (McDonald, 2013). Media studies are also expanding into interdisciplinary work under term "media industries studies" Schatz (2014). Pick et al (2015) also note a tension between creative industries and management studies, and suggest that 'creative industries management' is both an oxymoron and an opportunity. This points to a general frustration over on-going tensions between media economics and political economy approaches to the study of media industries and cultural products Wasko and Meehn (2013).

A concerted attempt to persuade reluctant audiences of the importance and potential of economic analysis can be found in Bahkshi et al (2007). The authors seek to persuade stakeholders in cultural policy that economics can, and should, bolster the case for the arts. The authors, along with O'Brien (2010), provide critiques of economic methodologies and note the 
measurement challenges the intangible nature of culture creates. Bahkshi et al make their case on the basis that the special pleading of the arts/cultural policy implies that, "arts funding choices should be made independent of their effects on society." Economics, instead, offers a means to avoid this 'arts exemption' and strengthen the case for the arts.

\section{Tensions with Neoclassical Economics}

The reluctance of policy audiences for cultural economics speaks to a wider critique of neoclassical economics. Neoclassical economics has long been criticised; this criticism experienced a sharp uptick in the 1990s as detailed in Thomspon (1997). Noted critic McCloskey (McCloskey, 1998) condemns 'the rhetoric of economics' and the utility maximising approaches influenced by Ayn Rand's objectivism. McCloskey's critiques are directed at the discipline as a whole, and cultural economics and neoclassical economics are not mutually exclusive. The McCloskey school of thought, when combined with the policy scepticism noted by Peacock, mean that cultural economics is prone to external and internal criticism. Rational choice theory is a particular target of condemnation and, as noted by Throsby (2001), leads to the expectation that all behaviours can be fully accounted for in economic models, without regard to social, cultural or historical factors. O'Brien (2014), using the tensions between the humanities and economics as an analytical framework, largely confirms this view and details oppositions to economic constructs of individual rationality in UK cultural policy. Throsby $(2001,2012)$ also notes this tension, which he suggests stems from economics' emphasis on the individual in contrast to the, by definition, collective emphasis of culture. He also notes (1994) that neoclassical views of tastes (the utility function) accommodate taste for the arts, but that this may fail to account for the irrationality of demand for art. However, he also notes that, "the aggregate behaviour of consumers and of artists can be modelled in ways that are mostly consistent with economic theory." To summarise, scepticism and criticism of the neoclassical economic approach abounds, and is particularly sharp in the creative industries and in cultural policy as a whole. 


\section{IP, Innovation and Creativity}

\section{Creativity and Innovation}

While cultural policy has struggled to hold the attention of its intended audience, analysis of innovation has an eager audience. In developed economies, politicians, policy makers and economists have a collective obsession with innovation in the hopes that it contributes to economic growth. These obsessions, and the associated economics of innovation, benefit from neoclassical, mainstream economic roots. While critics of the approach exists (e.g. feminist critiques as detailed later), the innovation-development-growth narrative is firmly entrenched in the political economy. A long-term trend of developed economies moving away from manufacturing based to service based economies, has led to a greater emphasis on knowledge and the emergence of the "knowledge economy" as discussed in Garnham (2005). The focus on this new knowledge-based paradigm has promoted further analysis of innovation, which has led innovation-focused economists to look at creativity. For example, Lee and Rodriquez-Pose (2014) who examine the 'innovativeness' of the creative industries and creative occupations; and The Work Foundation and NESTA's 2007 report that argues, "creativity and innovation are overlapping concepts. In the main, creativity ... is about the origination of new ideas ... while innovation is about the successful exploitation of new ideas." Similarly, Doyle (2016) notes a growing emphasis on innovation in the creative economy and media studies. This innovation approach follows a path dependency from the neoclassical understanding of innovation, particularly from an industrial organisation or economic development foundation. As cultural economics also begins to look further at innovation and creativity arguments, with a focus on the creative industries, analysis from both neoclassical and cultural perspectives are meeting. This section discusses these perspectives, and their reflection in IP debates.

Economists link innovation to the creative industries, often done with the intent of proving the economic value of the creative industries, and implicitly discuss creativity. For example, Bakhshi and McVittie (2009) detail how the creative industries enable other industries to be more innovative. Muller et al 
(2009) notes three innovation impacts from the creative industries: creative industries contribute to the innovative potential of an economy, they may create inputs for innovation elsewhere in the economy and may serve a pull function as consumers of innovation. Howkins (2001) argues that creativity is not an economic activity but can become so when transformed into an 'idea with economic implications or a tradable product." This goes part way to fitting the classic definition of an innovation as an applied invention.

Concepts of creativity, as detailed in (Towse, 2006) became more popular within cultural economics with Frey (1997). Howkins (2001) devotes his entire book to the role of creativity and the concept of the creative economy.

Previously, economics flirted with the concept of creativity by combining psychological research on creativity with economics. This approach often took the form of examination of creativity in the marketplace in the form of entrepreneurship and management (e.g. works in the Journal of Creative Behaviour such as the 1988 Volume 22 Number 3 special edition including Fernald (1988) "The Underlying Relationship Between Creativity, Innovation and Entrepreneurship," or the Creativity and Innovation Management journal for example Jeffcut and Pratt (2003) "Managing Creativity in the Cultural Industries"), or in the analysis of human capital (e.g. Rubenson and Runco, 1992 whose theories were taken up more by psychologists than economists). Recent years have seen, as discussed earlier, creativity to be associated more with innovation and the creative industries.

However, Garnham (2005) argues that the addition of creativity, rather than a critique or extension of the economics of innovation, is instead an attempt by cultural policy to capture the prestige of innovation. Like Hesmondhalgh and Pratt (2005), Garnham notes the cultural policy tensions between creators (the purveyors of creativity) in creative occupations, and rightsholders (typically large corporations) arising from innovation/creativity approaches to creative industries introduces. These tensions can be seen in intellectual property policy, as discussed in the next section. 
This relationship between creativity and innovation is an evolving one, and highlights the challenges faced by cultural economics. The economics of innovation, particularly as related to economic growth and development, are well established and reflect a distinctly science focus. This focus on science, and the narrow definition of innovation, is sometimes construed as a bias and challenged by proponents of the creative or knowledge economy (e.g. Rushton 2003, and feminist critiques of innovation and measurements of economic growth.)

\section{Intellectual Property}

The interaction between creativity, the creative industries and innovation has become more obvious in recent years with the rise of interest in IP policy. Major changes in the legal structure of IP have been marked by a step change introduced by the World Trade Organisation's 1995 Trade-Related Aspects of IP (TRIPS) agreement, which harmonised and strengthened IP across the world. This, along with changes in markets and technology, dominated by the advent of the Internet and the digital era, have challenged existing IP structures, in particular that of right most relevant to the creative industries, copyright. The relationship of the creative industries and copyright is so strong, that at various times, the term 'the copyright industries' has served as a synonym for creative industries. Towse (2006) made the case for copyright as falling within the realm of cultural economics. IP, which by definition only protects original contributions, also reflects the infinite variety (Caves 2000) and "extreme case of a heterogeneous commodity" Throsby (1994) by which each unit of the creative industries output is unique. As a result, IP policy has become a string in the cultural economist's bow.

The predominance of IP is not without its critics. Potts (2009) notes that the DCMS definition of the creative industries rests on a connection between creativity and IP that emphasises, "creativity as an input and IP as an output, a view that implicitly presumes that the value of the creative industries is ultimately in consumption of these creative outputs." Muller et al (2009) also note that IP is considered the main output of the creative industries, as opposed to goods and services. Potts is critical of this approach, as he argues 
that the outputs of the creative industries play an important role in innovation as a whole, rather than being defined by the production and consumption of end outputs.

Feminist interpretations of IP provide further critique of IP and neoclassical economics. Bawra and Rai $(2002,2004)$ argue IP denies the contribution of women to knowledge by taking a narrow approach to knowledge and assigning it to realms that have traditionally excluded women. Halbert (2006) notes the lack of IP protection for the outputs of female knowledge. Halbert in particular relates this discussion to the creative industries by providing case studies on quilting and knitting, two creative practices dominated by women, as lying predominately outside the IP framework. Santhosh and Sengupta (2011) argue IP undervalues the 'gendered science' of traditional knowledge. Collectively, the development of 'creativity' in the cultural economics sense, along with the feminist perspective, suggest that the definition of innovation, as protected by IP, is too narrow. This plays into wider critiques of neoclassical economics' core assumption of rationality and utility; however, as Bakhshi et al (2007) note, this critique is often directed at bad economics rather than a systematic failure of economic approaches.

Economics' love of innovation and subsequent focus on IP pre-dates the cultural economic analysis of IP. As a result, discussions on creativity follow a path dependency into innovation and specific constructs of IP. The next section highlights this by detailing the evolution of the economic analysis of trade marks, in contrast to the analysis of the relatively newer rights of Traditional Knowledge (TK) and related rights.

Creative Industries and IP

Having established the relevance of IP policy to cultural economics, this section of the chapter uses examples of IP to further illustrate the challenges facing cultural economics as a critique of neoclassical economics. 


\section{Approaches to IP}

IP policy, and the laws which create it, generally exists to solve the problem of intangibility. The intangible nature of creativity and innovation means that ideas can easily be appropriated, and, in contrast to physical property, this appropriation is difficult to control. This can undermine creators' ability to recoup their investments, or profit, from their creations. For simplicity, I shall use the term 'creator' as being more inclusive to the creative industries than the more common 'innovator' used in general economics. IP policy seeks to create property rights over the intangible to bolster ownership and control of innovation and creativity.

Justifications for why societies should have property rights over the intangible are dominated by two ${ }^{x}$ main approaches. These are, IP rights as intrinsic rights, and IP as an incentive to innovate. Granstrand (2000) refers to these, respectively, as deontological approaches based on the intrinsic, moral rights and arguments that fall outside the economic perspective; and consquentialist approaches founded in the economic implications (e.g. incentive to innovate) of the legal structure of IP. These two approaches are often incompatible, with the incentive-to-innovate theory gaining traction in recent decades.

Approaching IP rights as intrinsic rights comes from a Lockean perspective in which individuals own the fruit of their own labour (Hettinger 1989, Grandstrand 2000). Using this framework, the creativity and innovation stemming from an individual's application of their labour should be owned by said individual. IP rights allow individuals rights over their outputs. This approach is also known as labour-dessert theory and is an approach popular with lawyers and existing owners of IP rights. The focus rests on the benefits to the individual creator.

In contrast, the traditional economic approach to IP is to construe it as an incentive to innovate (Scotchmer 2004, Lemley 2005). In this model, often referred to as the social contract theory, the creator is rewarded with property rights in the form of IP. These rights allow the creator to appropriate the returns to their efforts, and serve as an incentive to innovate. While society may incur higher costs and lower quantities because of the monopoly 
conditions generated by IP rights, society is rewarded with long-term innovation. This approach, crucially, also requires the expiration of IP rights so that, on expiration, the knowledge contained falls into the public domain where it will spur further innovation. The incentive-to-innovate theory is focused ultimately on economic growth and the benefits to society, and assumes innovation leads to economic growth and development.

The incentives-to-innovate theory of IP has served economics well in analysing the IP rights of patents and copyright. Economics is largely comfortable with viewing patents and copyright as economic policies. The same cannot be said, however, for trade marks, traditional knowledge (TK), and Geographical Indications (GI); all three of which are relevant intellectual assets for the creative industries. These rights are heavily linked to the creative industries by way of branding, arts, textiles, design and advertising. Economics tends to be wholly uncomfortable with these rights as serving economic purposes as they do not fit the social contract. This tension between the neoclassical, incentive-to-innovate theory, and these noncompliant rights highlights the challenges cultural economics continues to face.

\section{Incompatible IP: The cases of Trade marks, TK and GI}

Patents have dominated economists' analysis of IP, which is likely due to the relative wealth of data in this area and patents as fitting the science bias of constructs of innovation. Recent decades have seen an expansion of economic analysis to copyright, trade marks and design rights. In the case of the former, because of the dramatic changes in technology and its market consequences, and in the case of the two latter, likely due to the trend in national IP offices publishing data in these areas. However, trade marks, along with $\mathrm{TK}$ and $\mathrm{GI}$, do not easily fit the social contract theory and remain an awkward fit as an economic policy. 


\section{Trade marks}

Trade marks ${ }^{\mathrm{xi}}$ are an important intellectual asset for most firms, and in particular, as a means of protecting the creative outputs of the advertising and graphic design sectors. However, trade marks lack two key characteristics of the social contract theory: they do not expire as long as renewal fees are paid, and they do not necessarily qualify as innovation. Assuming the owner of a trade mark pays their renewal fees, a trade mark can potentially last forever. Trade marks are traditionally not considered a form of innovation, a topic discussed in further below.

Two foundational papers on the economics of trade marks are those of Landes and Posner (1987), and Economides (1998). Both of these papers argue that trade marks exist primarily to promote economic efficiency, rather than innovation. Landes and Posner further posit that trade marks serve to incentivise linguistic innovation. Economides (1988), however, is critical of the role of trade marks in distorting competition and market equilibria. The bulk of subsequent analysis has taken a neoclassical approach and the economic scholars here do not self-identify as cultural economists.

A standard economic interpretation of trade marks is their role in promoting efficiency by reducing information gathering costs via signalling to consumers. A trade mark is an exclusive mark that signals a brand's reputation (or lack thereof). This reputation will consist of a variety of factors influencing consumer decision-making. The mark is an efficient way of signalling quality, an important factor, to the consumer. This signal reduces search costs as, at a glance, the consumer will have information about the quality about a good, such as taste, provenance, etc. Thus, marks reduce the information asymmetries between consumers and producers and promote efficiency.

Initially, economic analysis suggested that branding was useful for a brand owner to increase their market share, but at the expense of another's (discussed in Putsis, 1998). Using this approach, the branding protected by trade marks operates in a zero sum game. Following this line of thought, trade marks do not promote innovation because they operate in a zero-sum game. Lemley (2004) is particularly scathing on justification of trademarks: 
"Unlike patents and copyrights, trademark law and the right of publicity do not exist to encourage the creation of new brand names, personal names, or likenesses. There is no affirmative social interest in encouraging their proliferation, and, in any event, the fixed costs invested in creating a new name are so minimal that it is hard to imagine that creating one would require incentive."

However, starting in the mid-90s (Putsis 1998) economists explored the relationship between branding, promotions (temporary discounts or details) and sales of a particular category of goods, particularly in Fast Moving Consumer Goods (FMCG). This research, and further discussions (Corrado and Hao, 2013) suggests that the branding incentivised by trade marks can result in innovation. Additionally, there are discussions on trade marks and branding as a good indicator of innovative activities ${ }^{\mathrm{xi}}$ and branding as facilitating the introductions of innovations to markets. Greenhalgh and Rogers (2007), adopting a Shumpterian approach to innovation, examine the relationship between trade mark and innovation activities in firms and find that, "applications for trade marks are suggestive of product innovation." Thus, if trade marks can promote or embody innovation, there is room for them to fit in an incentive-to-innovate interpretation of IP.

Other economic analysis of trade marks extend to their role in facilitating firm's appropriation of the returns to their investments in reputation. The leads to the conclusion that brands are often a firm's most valuable asset (discussed and critiqued Klein (2010)). Other analysis examines the role of trade marks in conspicuous consumption, ala Veblen. The use of trade marks, and trade mark policy, has also been examined in competition discussions and policy-specific analysis such as the optimal structure of trade mark registration processes and registries (e.g. Von Graevenitz, 2013.) A rare explicitly cultural economic analysis by Cuccia et al (2008) looks at the role of collective trade marks in the San Gregorio Armenio district of Naples. Known for its hand carved nativity scenes, the authors examine, from a creative cluster and regional government perspective, the potential use of trade marks to, "promote market incentives sustaining local development and preserving or enhancing the common knowledge." The authors conclude a collective 
trade marks would increase prices of the nativity scenes by $10 \%$. Generally, economics finds trade marks to be an important intangible asset for firms and collectives.

Trade marks illustrate the evolution of the economic analysis of IP. Whereas early focus of analysis focused on the signalling and efficiency aspects of trade marks, more recent analysis has incorporate creativity and innovation aspects of branding. These contemporary arguments are not incompatible with neoclassical economics and suggest that development of cultural economics does not necessarily require departure from the mainstream, neoclassical perspective that is so often the subject of critique. The same cannot be said of the current state of economic analysis of TK and GI.

\section{Traditional Knowledge (TK) and Geographical Indications (GI)}

Both TK and GI are relatively new types of IP as they have only existed in law and policy in the last century. Zappalaglio (2013) describes the origins of TK in international policy debates as starting in 1948. Monten (2005) notes that GI was largely unrecognised until the mid 1990s in TRIPs. TK, however, exists legally in predominately non-binding agreements whereas $\mathrm{GI}$ is enshrined in law in many jurisdictions (e.g. the EU.) The relative youth of these types of IP goes in part to explain their absence from cultural economics. However, in both cases, these IP are based on cultural and creative goods and services.

Yudice (2009) notes tensions between IP regimes and anthropological approaches to culture. He argues that uses of culture cluster around two main poles: anthropological approaches that focus on values and symbolic uses, and a creative element that focuses on innovation. IP falls under the latter, and leads to discordant cultural policies where IP impinges on cultural policies, such as those promoting access to cultural goods. Akin to his anthropological descriptor, Doyle (2016) explains policy interventions in indigenous content media production as acting on "socio-cultural grounds." Garnham (2005) argues that the creative approach and its policies, under the knowledge economy focus, is now inseparable from Information and Communications Technology (ICT) policy. However, ICT, which is a relative 
new phenomena, clearly does not interact with the bulk of issues regarding TK, which is long-established. The tension between these anthropological and creative approaches can be seen in TK and GI policy.

\section{Traditional Knowledge (TK)}

TK, which covers all manners of intangible assets of a community, speaks to the collective emphasis of culture. At present, economic analysis, with its individual, innovation focus, is at odds the collective, traditional focus on TK.

The World IP Organisation defines TK as,

Knowledge, know-how, skills and practices that are developed, sustained and passed on from generation to generation within a community, often forming part of its cultural or spiritual identity... TK in a general sense embraces the content of knowledge itself as well as traditional cultural expressions, including distinctive signs and symbols associated with TK. TK in the narrow sense refers to knowledge as such, in particular the knowledge resulting from intellectual activity in a traditional context, and includes know-how, practices, skills, and innovations. WIPO (2015)

A subset of TK is Traditional Cultural Expressions (TCE),

Also called "expressions of folklore", [TCE] may include music, dance, art, designs, names, signs and symbols, performances, ceremonies, architectural forms, handicrafts and narratives, or many other artistic or cultural expressions. ... Their protection is related to the promotion of creativity, enhanced cultural diversity and the preservation of cultural heritage. (WIPO 2015)

TK is a very awkward fit for a neoclassical, incentive-to-innovate analysis of IP. To start, the rights are poorly defined as TK itself lacks a clear definition. Further, TK are most often not expressed in any fixed way and their ownership is unclear, both of which make identifying the protected knowledge difficult. TK itself is unlikely to be traded in a monetary fashion and thus arguments in favour of recouping rewards to innovation are thin. Additionally, 
by definition, TK is traditional and any rights may actively discourage innovation. However, the codification of the knowledge contained in TK may promote its diffusion and subsequent innovation; thus, TK may encourage further innovation.

A common economic argument in favour of innovation is the economic growth and development of indigenous communities. These communities are often rural and economically poor. Protection of TK 'owned' by these communities could foster local development. However, the development of a thriving market is dependent on many factors other than IP protection. The introduction of an IP right merely provides the right to exclude others from using the IP. The capabilities to translate TK into economic success may require skills (absorptive capacity) not present in the community, and the community could license to a third party. In this case, the TK may function as the equivalent of a natural resource with no long-term development impact. Dutfield (2005) is less pessimistic than this analysis, but notes that the development of goods and services incorporating TK exposes communities to the vagaries of the dominant economic system surrounding them. Yudice's concept of the 'anthropological' approach to culture, by focusing on a social, value-driven side of culture, neither introduces nor addresses this economic doom, which the 'creative' approach does.

In short, TK fails to fit the social contract, incentive-to-innovate economic interpretation of IP.

Stronger arguments in favour of TK lie outside the domain of neoclassical economics, but in the social, cultural and historical context described by Throsby (2001). As noted in a WIPO fact-finding mission report, the value of TK is in the community's cultural benefits. Discussions on IP frameworks in the Carribbean suggest that communities view their TK, " as an economic asset and as cultural patrimony.... [and] did not separate "artistic" from "useful" aspects of their intellectual creations and innovations." WIPO (2008). 
Economics is ill equipped to incorporate measurements of TK or cultural patrimony into its analysis. Financial valuations are difficult in any form of intangible asset such as IP, but cultural patrimony is even more ethereal. One possible angle for inclusion would be to consider cultural patrimony part of the community's utility function. This might capture some of the value and decision-making, but would be subject to the same market failures that form the basis of many approaches to cultural economics. This points to a contingent value methodology and choice modelling as potential solutions (O'Brien 2010). It may also be that the costs of creating such empirical, quantitative measurements are disproportionate to the benefits. This combination of methodological challenges and practical costs suggest that theoretical or qualitative, rather than empirical or quantitative, analysis may be better deployed to inform TK policy.

Current economic thinking does not allow for TK to fit into an innovation approach to IP. The same could be said for trade marks, however recent analysis, adopting a wider definition of innovation, suggests trade marks can fit. The analysis of TK may follow a similar path. As a cultural policy, TK suffers from this lack of positive economic interpretation, in addition to its already tenuous position in international policy debates. This suggests Yudice's anthropological approach is at the core of justifications for TK, and attempts to fit TK into an overarching creativity and innovation approach are inappropriate. This is not to say that economic analysis cannot inform cultural policy, but that a standard social contract/incentives-to-innovate approach is incomplete in its current form. Revisiting the scope of economic analysis of the benefits of creativity and innovation to capture social values may introduce needed flexibility into social contract theory. This might benefit from beginning economic analysis of IP for a cultural economics perspective rather than an industrial organisation/growth perspective. In short, adopting an intradisciplinary economic approach. Further analysis is required.

\section{Geographical Indications (GI)}


GI, which overlap with TK, suffer from similar challenges in fitting social contract theory and innovation arguments. Unlike other rights, they confer no freedom to contract or freedom to license. Instead of incentivising innovation, Gls can actively discourage innovation. A GI provides legal structure to the branding and quality of a product associated with a particular geographical region. The neoclassical economic justification for $\mathrm{Gl}$ is additionally undermined by the overlapping coverage of other rights (for example, collectively owned trade marks serve a similar purpose.)

A geographical indication $(\mathrm{GI})$ is a sign used on products that have a specific geographical origin and possess qualities or a reputation that are due to that origin. In order to function as a GI, a sign must identify a product as originating in a given place. In addition, the qualities, characteristics or reputation of the product should be essentially due to the place of origin. Since the qualities depend on the geographical place of production, there is a clear link between the product and its original place of production. WIPO, 2015

Like trade marks, an economic argument for $\mathrm{Gl}$ is to protect producers from free riding by competitors. However, the long term economic benefits conferred on producers and these regions remains unproven. The introduction of a GI may benefit producers through legal protection, economic development and environmental concerns, but, like TK, these impacts are unclear. Furthermore, the GI may distort incentives and affect both the quality and quantity of the product.

The economic rhetoric focuses heavily on Gl's role in economic development of rural areas (Bramley 2011). However, these arguments are weaker if individual producers are owned by larger businesses where profits may not develop the local economy. Indeed, the production of wines and spirits has undergone significant consolidation ${ }^{\text {xiii }}$,iv in past years and, in these markets, the majority of production of GI goods is owned by large multi-nationals. This stands in contrast to the local, rural rationale for $\mathrm{GI}$. 
As with the impact on indigenous peoples with respective to $\mathrm{TK}$, the long-term impact of $\mathrm{Gl}$ on producers is uncertain. Existing producers may initially benefit from the price premium and reduced competition from products outside the $\mathrm{GI}$ protection, but cost inputs and distorted incentives may mean that the economic distribution of these benefits changes over time. Thus, the original economic goals of the introduction of a GI may not be realised.

GI have become more contentious as some countries seek to expand GI to non-agricultural products. These products are typically textiles such as pottery or woollens that still are strongly influenced by the environment in which they are produced. As a relatively new right ${ }^{\mathrm{xv}}$, non-agricultural $\mathrm{GI}$ are still developing and further refinement of the both the right, and the economic understanding, may occur. Yet to be fully considered by the literature is the appropriateness of government resources to protect rights not available to the general public.

While neoclassical economic analysis of trade marks has evolved to incorporate a wider understanding of the economic contribution of branding, the same cannot be said for TK and GI. However, cultural economics, with its well-developed understanding of cultural policy and creative industries, can contribute to this development and highlight the shortcomings of an incentiveto-innovate, social contract approach to IP.

\section{Conclusions}

Cultural economics continues to evolve as analysis of the creative industries, intellectual property policy and economics, both in economic literature and policy development, merge. As this chapter has detailed, discussions on innovation and creativity have led both innovation-focused and cultural economists to examine IP as a cultural and innovation policy. However, analysis of IP highlights the restrictions that traditional economics face when examining the realm of cultural policy and creative industries. While longstanding IP such as patents and copyright fit a neoclassical, incentive-toinnovate approach and are satisfied with rational choice theory and the maximisation of profits and utility, emerging IP rights are not. Economics' focus on the individual falters when faced with the collective approach of 
rights such as TK and GI. However, the evolution of economic analysis of trade marks suggests that economic tools and analysis have the potential to adapt.

Given the progression of IP as a topic of international negotiations, cultural economics' interest in IP is likely to continue. IP as a cultural policy merits further examination. Areas to consider for future research are further examination of the impact on economic development stemming from IP such as TK and GI. Progression of the understanding of innovation, to include 'soft' innovation and creativity, will likely reformulate innovation policy. Copyright, only mentioned in passing in this chapter, is very poorly understood empirically and may benefit from the growth in data availability stemming from the digital era. Ultimately, these investigations may lead to a departure from, or further developments of, incentive-to-innovate approaches to IP. 


\section{References}

BAKER, D. \& EVANS, W. 2013. A handbook of digital library economics operations, collections and services.

BAKHSHI, H., FREEMAN, A. \& HITCHEN, G. 2009. Measuring Intrinsic Value. How to Stop Worrying and Love Economics http://www. missionmodelsmoney. org. uk/papers/measuring-intrinsicvalue/(dostęp: o 1.10. 2011).

BAKHSHI, H. \& MCVITTIE, E. 2009. Creative supply-chain linkages and innovation: Do the creative industries stimulate business innovation in the wider economy? Innovation, 11, 169-189.

BARWA, S. \& RAI, S. M. 2003. Knowledge and/as power: a feminist critique of trade related intellectual property rights. Gender, technology and development, 7, 91-113.

BLAUG, M. 2001. Where are we now on cultural economics. Journal of economic surveys, $15,123-143$.

CHERRIER, B. 2014. Classifying Economics: a History of the JEL Codes. Available at SSRN 2537382.

CORRADO, C. A. \& HAO, J. 2013. Brands as productive assets: Concepts, measurement, and global trends. Background research for the.

CUCCIA, T., MARRELLI, M. \& SANTAGATA, W. 2008. Collective trademarks and cultural districts: the case of San Gregorio Armero, Naples. Cooke, P., y Lazzeretti, L., Creative Cities, Cultural Clusters and Local Economic Development, Cheltenham, Edward Elgar, 121-135.

DAVID PICK, D. P. W., PROFESSOR JULIA CONNELL AND DR LOUIS ANDRE GENESTE, DR, PICK, D., WEBER, P., CONNELL, J. \& GENESTE, L. A. 2015. Theorising creative industry management: rebooting the woolly mammoth. Management Decision, 53, 754-762.

DOYLE, G. 2016. Creative economy and policy. European Journal of Communication, 31, 33-45. 
DUTFIELD, G. Harnessing traditional knowledge and genetic resources for local development and trade. International seminar on intellectual property and development. WIP-UNCTAD-UNIDO-WHO-WTO, Geneva, 2005.

ECONOMY, C. 2008. Report 2008: The Challenge of Assessing the Creative Economy: towards Informed Policymaking, UNDP-UNCTAD.

FREY, B. 1994. Art: The Economic Point of View. In: PEACOCK, A. \& RIZZO, I. (eds.) Cultural Economics And Cultural Policies. Springer Netherlands.

FREY, B. S. 1997. Not just for the money. Books.

GARNHAM, N. 2005. From cultural to creative industries: An analysis of the implications of the "creative industries" approach to arts and media policy making in the United Kingdom. International journal of cultural policy, 11, 15-29.

GHOSE, A., SMITH, M. D. \& TELANG, R. 2006. Internet exchanges for used books: An empirical analysis of product cannibalization and welfare impact. Information Systems Research, 17, 3-19.

GRANSTRAND, O. 2000. The economics and management of intellectual property : towards intellectual capitalism, Cheltenham [u.a.], Edward Elgar.

GREENHALGH, C. \& ROGERS, M. 2007. Trade Marks and Performance in UK Firms: Evidence of Schumpeterian Competition through Innovation.

HALBERT, D. 2006. Feminist interpretations of intellectual property. Am. UJ Gender Soc. Pol'y \& L., 14, 431.

HESMONDHALGH, D. 2005. Media and cultural policy as public policy: the case of the British Labour government. International journal of cultural policy, 11, 95-109.

HESMONDHALGH, D. \& PRATT, A. C. 2005. Cultural industries and cultural policy. International journal of cultural policy, 11, 1-13. 
HETTINGER, E. C. 1989. Justifying Intellectual Property. Philosophy \& Public Affairs, 18, 31-52.

HOWKINS, J. 2002. The creative economy: How people make money from ideas, Penguin UK.

KLEIN, N. 2010. No space, no choice, no jobs, no logo.

LANDES, W. M. \& POSNER, R. A. 1989. An economic analysis of copyright law. The Journal of Legal Studies, 325-363.

LEE, N. \& RODRÍGUEZ-POSE, A. 2014. Creativity, cities, and innovation. Environment and Planning A, 46, 1139-1159.

LEMLEY, M. A. 2004a. Ex ante versus ex post justifications for intellectual property. The University of Chicago law review, 129-149.

LEMLEY, M. A. 2004b. Property, intellectual property, and free riding. Tex $L$. Rev., 83, 1031.

MCCLOSKEY, D. N. 1998. The rhetoric of economics, Univ of Wisconsin Press.

MCDONALD, P. 2013. Introduction. Cinema Journal, 52, 145-149.

MENDONÇA, S., PEREIRA, T. S. \& GODINHO, M. M. 2004. Trademarks as an indicator of innovation and industrial change. Research Policy, 33, 1385-1404.

MONTÉN, L. 2005. Geographical Indications of Origin: Should They Be Protected and Why-An Analysis of the Issue from the US and EU Perspectives. Santa Clara Computer \& High Tech. LJ, 22, 315.

MÜLLER, K., RAMMER, C. \& TRÜBY, J. 2009. The role of creative industries in industrial innovation. Innovation, 11, 148-168.

NESTA, T. W. F. A. 2007. Staying Ahead: The Economic Performance of the UK's Creative Industries - Creative Blueprint [Online]. Available: http://creative-blueprint.co.uk/library/item/staying-ahead-the-economicperformance-of-the-uks-creative-industries [Accessed]. 
O'BRIEN, D. 2010. Measuring the value of culture: a report to the Department for Culture Media and Sport, Department for Culture, Media and Sport.

O'BRIEN, D. 2014. Cultural value, measurement and policy making. Arts and Humanities in Higher Education, 1474022214533892.

PEACOCK, A. 2004. THE CREDIBILITY OF CULTURAL ECONOMISTS'ADVICE TO GOVERNMENTS. CONTRIBUTIONS TO ECONOMIC ANALYSIS, 260, 165-178.

POTTS, J. 2009. Introduction: creative industries \& innovation policy. Innovation, 11, 138-147.

PUTSIS JR, W. P. 1998. Are Brand Promotions Just a Zero Sum Game-or Can They Increase the Size of the Pie? Business Strategy Review, 9, 21-32.

RUBENSON, D. L. \& RUNCO, M. A. 1992. The psychoeconomic approach to creativity. New ideas in Psychology, 10, 131-147.

RUSHTON, M. 2003. Cultural diversity and public funding of the arts: A view from cultural economics. The journal of arts management, law, and society, 33, 85-97.

SCHATZ, T. 2014. Film Studies, Cultural Studies, and Media Industries Studies. Media Industries, 1.

SCHUMPETER, J. 1942. Creative destruction. Capitalism, socialism and democracy.

SCOTCHMER, S. 2006. Innovation and incentives, Cambridge, Mass., MIT Press.

SENGUPTA, S. M. R. A. R. 2011. Trade, Intellectual Property Rights (IPRs) and Gender Issues in India. Trade and Gender Briefs' Series. India. InditeGlobal, New Delhi,: Third World Network (TWN) and Heinrich Boell Foundation (HBF).

STONEMAN, P. 2010. Soft innovation: economics, product aesthetics, and 
the creative industries, Oxford University Press.

THOMPSON, H. 1997. Ignorance and ideological hegemony: A critique of neoclassical economics. Journal of Interdisciplinary Economics, 8, 291305.

THROSBY, D. 1994. The production and consumption of the arts: A view of cultural economics. Journal of economic literature, 32, 1-29.

THROSBY, D. 2012. Why should economists be interested in cultural policy? Economic Record, 88, 106-109.

THROSBY, D. \& THROSBY, C. 2001. Economics and culture, Cambridge university press.

TOWSE, R. 2006. Copyright and artists: a view from cultural economics. Journal of Economic Surveys, 20, 567-585.

TOWSE, R. 2010. A textbook of cultural economics, Cambridge University Press.

TOWSE, R. 2014. Advanced introduction to cultural economics, Edward Elgar Publishing.

VON GRAEVENITZ, G. 2013. Trade mark cluttering-evidence from EU enlargement. Oxford Economic Papers, 65, 721-745.

WELDON, W. 1972. Why Creativity? An Analogy to the Economics of Supply and Demand*. The Journal of Creative Behavior, 6, 55-60.

WIPO 2008. WIPO Regional Expert Meeting on the Establishment of a Caribbean Framework for the Protection of Traditional Knowledge, Folklore and Genetic Resources.

YÚDICE, G. 2009. Cultural Diversity and Cultural Rights. Hispanic Issues Online.

ZAPPALAGLIO, A. 2013. Traditional Knowledge: Emergence and History of the Concept at International Level. Available at SSRN. 
${ }^{i}$ Including, but not limited to, the creative economy, the copyright industries, the creative industries, the cultural industries, cultural-political economy, and the creative classes.

ii The list of these industries, shown in "Creative Industries Mapping Documents 1998”, is available at https://www.gov.uk/government/publications/creativeindustries-mapping-documents-1998.

iii ECONOMY, C. 2008. Report 2008: The Challenge of Assessing the Creative Economy: towards Informed Policymaking, UNDP-UNCTAD. p. 9 and repeated in the 2010 version of the report.

iv TOWSE, R. 2010. A textbook of cultural economics, Cambridge University Press. P. 105.

"Thorstein Veblen's seminal work, "Theory of Leisure Class" in 1898, could be classified as cultural economics. Works by Adam Smith (1700s) also consider the market for arts.

${ }^{\mathrm{vi}}$ (Cherrier, 2014) p. 35

${ }^{\text {vii }} \mathrm{He}$ also notes, unfortunately for your author, the challenges of a career as a cultural economist are many. He argues that foundations favour funding research building on well-established areas of economic analysis, one-off funding is rare, the opportunity costs of such careers are high, and the audience for economic research in the arts is limited.

viii (Peacock, 2004), P. 177.

${ }^{\text {ix }}$ Ibid, P. 175.

${ }^{\mathrm{x}}$ There is an emerging third nexus, which involves a near or total rejection of IP, which is not discussed here.

${ }^{x i}$ Defined by WIPO (2015), as "A trademark is a distinctive sign which identifies certain goods or services as those produced or provided by a specific person or enterprise." Available at http://www.wipo.int/trademarks/en/trademarks.htrade marksl xii Further on the use of trade marks as a complementary measurement in industrial and innovation analysis can be found in Mendoca et al (2004)

xiii Emler, R. (June 13, 2012), "Spirits Firms Poised for Further Consolidation," The Drinks Business, Available at http://www.thedrinksbusiness.com/2012/06/spirits-firms-poised-for-further-consolidation/

xiv Morss, E. (January 14, 2012), "The Future of the Global Wine Industry," Morss Global Finance, available at http://www.morssglobalfinance.com/the-future-of-the-global-wine-industry/

${ }^{x v}$ The first formalized system of GI is that of France which was put into law in the early 1900s. The European Commission began a consultation on NAGI in 2014. 